\title{
The puzzle of chloroplast vesicle transport - involvement of GTPases
}

\section{Sazzad Karim and Henrik Aronsson*}

Department of Biological and Environmental Sciences, University of Gothenburg, Gothenburg, Sweden

\section{Edited by:}

Takashi Ueda, The University of Tokyo, Japan

\section{Reviewed by:}

Takehito Inaba, University of Miyazaki, Japan

Shuh-ichi Nishikawa, Niigata

University, Japan

\section{*Correspondence:}

Henrik Aronsson, Department of

Biological and Environmental

Sciences, University of Gothenburg,

Box 461, 40530 Gothenburg,

Sweden

e-mail: henrik.aronsson@bioenv.gu.se
In the cytosol of plant cells vesicle transport occurs via secretory pathways among the endoplasmic reticulum network, Golgi bodies, secretory granules, endosome, and plasma membrane. Three systems transfer lipids, proteins and other important molecules through aqueous spaces to membrane-enclosed compartments, via vesicles that bud from donor membranes, being coated and uncoated before tethered and fused with acceptor membranes. In addition, molecular, biochemical and ultrastructural evidence indicates presence of a vesicle transport system in chloroplasts. Little is known about the protein components of this system. However, as chloroplasts harbor the photosynthetic apparatus that ultimately supports most organisms on the planet, close attention to their pathways is warranted. This may also reveal novel diversification and/or distinct solutions to the problems posed by the targeted intra-cellular trafficking of important molecules. To date two homologs to well-known yeast cytosolic vesicle transport proteins, CPSAR1 and CPRabA5e (CP, chloroplast localized), have been shown to have roles in chloroplast vesicle transport, both being GTPases. Bioinformatic data indicate that several homologs of cytosolic vesicle transport system components are putatively chloroplast-localized and in addition other proteins have been implicated to participate in chloroplast vesicle transport, including vesicle-inducing protein in plastids 1 , thylakoid formation 1, snowy cotyledon 2/cotyledon chloroplast biogenesis factor, curvature thylakoid 1 proteins, and a dynamin like GTPase FZO-like protein. Several putative potential cargo proteins have also been identified, including building blocks of the photosynthetic apparatus. Here we discuss details of the largely unknown putative chloroplast vesicle transport system, focusing on GTPase-related components.

Keywords: cargo protein, chloroplast, clathrin, COPI/II, GTPase, Rab, SAR1, vesicle transport

\section{INTRODUCTION}

Eukaryotic cells contain an endomembrane system that delimits organelles with specific functions. These organelles can synthesize various lipids and membrane proteins, but not all of the molecules they require. Thus, diverse lipids, proteins, and hormones are transferred between these organelles, and both to and from the plasma membrane, via small membrane-enclosed sacs called vesicles that bud and dissociate from the donor membrane of one organelle, move then dock and fuse with the acceptor membrane of another organelle (Battey et al., 1999; Lee et al., 2004). Most vesicles have specialized functions related to the cargo they transport (Bonifacino and Glick, 2004; Faini et al., 2013). For instance, some organelles, e.g., lysosomes and vacuoles, host cellular digestion and waste management systems and associated vesicles play key roles in recycling molecules through the endosomal pathway (Dingle, 1968; Mullins and Bonifacino, 2001; Luzio et al., 2007; Grant and Donaldson, 2009). Efforts to elucidate the systems for transporting cargos of vital molecules through the ER, Golgi, secretory granules, and plasma membrane from donor to target membranes were honored with the Nobel Prize in Physiology and Medicine in 2013. More specifically, the prize was awarded to Rothman, Schekman, and Südhof for contributions toward unraveling vesicle transport mechanisms in the yeast Saccharomyces cerevisiae and neurotransmitter transport mediated by synaptic vesicles in mammals (Südhof, 2004; Mellman and Emr, 2013).

The possibility that a vesicle-based system may shuttle important molecules between the ER, Golgi, and secretory organelles was initially raised in the 1970s, and vesicle-like structures were first observed in early transelectron microscopic (TEM) studies of pancreatic exocrine cells (Palade, 1975). A general hypothesis was subsequently formulated, postulating that molecules are transported by secretory systems via vesicles formed in a donor membrane then unloaded at a targeted acceptor membrane (Bonifacino and Glick, 2004). Three main classes of vesicles mediating transport have been described since then, based on their protein "coatings:" clathrin-coated vesicle (CCV), coat protein I and II (COPI and COPII) systems (Harrison and Kirchhausen, 2010; Faini et al., 2013). All of these types are morphologically similar, but they have distinct protein and lipid compositions, recognize and transport specific sets of cargo (Rothman, 1994; Schekman and Orci, 1996). CCVs participate in the late secretory pathway, i.e., the endocytic pathway between the Golgi and the plasma membrane (Bonifacino and Glick, 2004); COPI-coated vesicles 
function in both retrograde (Golgi to ER) and anterograde (within Golgi), while COPII-coated vesicles appear to be involved exclusively in transport from ER to Golgi (Lee et al., 2004; Bethune et al., 2006; Popoff et al., 2011).

Vesicles have also been found in other organelles, including chloroplasts and mitochondria (Morré et al., 1991b; von Wettstein, 2001; Soubannier et al., 2012). Many aspects of the nature and roles of these vesicles remain unknown. However, a decade ago eight putative chloroplast-localized homologs of known protein components of the COPII cytosolic vesicle transport system were identified in the model plant Arabidopsis (Andersson and Sandelius, 2004), and the list of COPII-related proteins was recently extended to more than 50 (Khan et al., 2013). Furthermore, putative COPII components were also identified in a recent search for orthologs in other plants, including the agriculturally important Solanum lycopersicum (tomato; Paul et al., 2014), and there are experimental indications that two of these proteins are involved in chloroplast vesicle transport (Garcia et al., 2010; Karim et al., 2014). In the following sections we first review current understanding of the three known vesicle transport systems in cytosolic secretory pathways, then apply it to interpret available information on vesicle transport in chloroplasts.

\section{GENERAL MECHANISMS OF VESICLE CYCLING AND COMPONENTS OF SECRETORY SYSTEMS}

Detailed information from yeast and mammalian cells indicate that the general mechanism of vesicle transport involves the following major steps. First, coat assembly is initiated through recruitment of multiple proteins, including membrane-associated small GTPases, transmembrane cargo proteins and Soluble NSF Attachment Protein Receptors (SNAREs) to a donor membrane. Mesh-like vesicles with concentrated cargos then bud through the assembly of coat components, which locally curve the membrane and govern the nascent vesicles' shape. Following scission from the donor membrane, via the action of accessory proteins, the mature vesicles are uncoated through inactivation of the small GTPases and activation of uncoating enzymes. Coat proteins are recycled for further rounds of vesicle budding, while the naked vesicles proceed to the acceptor membrane, guided by the cytoskeleton, where they are tethered by the combined action of a GTP-bound Rab GTPase and tethering factors. They are then docked through the binding of vesicle $\left(\mathrm{v}^{-}\right)$and target $(\mathrm{t}-)$ SNAREs (located on the vesicles and acceptor membrane, respectively) and fused with the acceptor lipid bilayer via activation of t-SNARE complexes. Finally, cargo molecules are transferred to the acceptor compartment and the SNAREs are recycled for a new transport round (Bonifacino and Glick, 2004). As already mentioned, three vesicle transport systems in plant cytosol, based on the coat proteins, have been characterized - COPII, COPI, and CCV - all of which are very similar to corresponding systems in yeast and mammals (Kirchhausen, 2000; Bassham et al., 2008). In secretory pathways, vesicles are known to deliver both soluble and membrane-bound proteins to target membranes, leading to the hypothesis that chloroplastic vesicle systems may also deliver proteins in addition to lipids (Khan et al., 2013).

The COPII secretory pathway, which transfers molecules from the ER to the Golgi, has been extensively studied in S. cerevisiae.
Identified components include five cytoplasmic proteins: Sar1, Sec13, Sec23, Sec24, and Sec31. Each of these proteins has a specific function, and all of them except Sec24 are essential for viability in yeast. In sharp contrast, multiple isoforms of COPII components are present in Arabidopsis, and reportedly functional in systematic yeast complementation assays (De Craene et al., 2014). Sar1, a small GTPase of the Arf (ADP-ribosylation factor) GTPase family (Vernoud et al., 2003), is initially recruited to the ER membrane and activated by the ER-associated Sec12, a guanine nucleotide exchange factor (GEF; Barlowe and Schekman, 1993). Sar1 subsequently binds to Sec23, a GTPase activating protein (GAP) that forms a coat subcomplex with a cargo-selecting protein, Sec24 (Bi et al., 2002). Another coat subcomplex consisting of Sec13 and Sec31 binds to the Sec23-Sec24 complex and is thought to be involved in membrane curvature (Lederkremer et al., 2001). Another essential component of the machinery, Sec16, is present at ER exit sites and hypothetically participates in COPII turnover and assembly at transitional ER sites; (Yorimitsu and Sato, 2012; Bharucha et al., 2013).

COPI systems are involved in intra-Golgi and Golgi-to-ER transport. In terms of vesicle formation and transport they are very similar to COPII systems (Kirchhausen, 2000; Trahey and Hay, 2010). The trans-Golgi network (TGN)-localized Arf-GEF protein Sec7 can initiate COPI vesicle formation by activating Arf1 (D'Souza-Schorey and Chavrier, 2006), a small GTPase that recruits a heptomeric complex from the cytosol (Orcl et al., 1993; Vernoud et al., 2003). The heptomer consists of two main subcomplexes: the F-COPI subcomplex (with $\beta, \gamma, \partial$, and $\zeta$ subunits) and the B-COPI subcomplex (with $\alpha, \beta^{-}$, and $\varepsilon$ subunits; Fiedler et al., 1996). In contrast to the COPII system, in which the Sarl GAP is an integral coat component, the Arf1 GTP hydrolysis that induces coat disassembly is mediated by a separate Arf GAP (Poon et al., 1999).

CCV systems, which are more complex than COPII and COPI systems, mediate plasma membrane endocytosis and transport from the TGN to endosomes and lysosomes (Trahey and Hay, 2010). In CCV clathrin heavy chain (CHC) and clathrin light chain (CLC) coat proteins form a geometrical scaffold, a triskelion, around the vesicle membrane (Kirchhausen and Harrison, 1981), and they are associated to adaptor protein (AP) complexes to bind to the membrane components. Similar to COPI, Arf GTPases are involved in the recruitment of a variety of coat subunits adaptor protein (AP) complexes. Five types of AP complexes (AP1 to AP5), involved in different pathways, have been recognized (Hirst et al., 2011). AP1 found on the TGN and endosomes, and AP2 found on the plasma membrane (Keen, 1990), attach clathrin to the donor membrane, select the protein cargo and recruit accessory proteins that regulate vesicle formation. AP3 and AP4, are also present on the TGN and endosomal membranes, but AP3 is mainly localized to endosomes and AP4 mainly to the TGN (Robinson and Bonifacino, 2001). AP4, and the fifth complex (AP5, localized to late endosomes) apparently participate in the late endosomal pathway (Hirst et al., 2011, 2013; Barlow et al., 2014). The Arabidopsis genome contains genes encoding putative members of all five classes (Bassham et al., 2008; Yamaoka et al., 2013). In both COPI- and CCV-mediated transport ARF GTPases are involved 
in the budding of vesicles from donor membranes (Memon, 2004).

Membrane fusion at the target membrane is mediated by the interaction of soluble SNARE proteins, with other proteins involved in the process, through their highly conserved SNARE domains. SNAREs are classified into two types: v-SNAREs (acting on the vesicle) and t-SNAREs (acting on the target membrane). During the membrane fusion one v-SNARE and three t-SNAREs interact to form a trans-SNARE complex in the vicinity of the target membrane. According to the amino acid residues glutamine (Q) or arginine (R) in the so-called 0-layer of the SNARE motif, SNAREs are divided into Q- and R-SNARES. The Q-SNAREs is further divided into three subgroups $(\mathrm{Qa}, \mathrm{Qb}$, and $\mathrm{Qc})$ depending on their locations in the core complexes, and in the R-SNARE glutamines are coordinated through hydrogen bonding to an arginine residue (Palfreyman, 2009; Kim and Brandizzi, 2012; El Kasmi et al., 2013).

Tethering factors form a bridge between vesicles and the target membrane and interact with Rab GTPases and SNAREs to ensure fusion. Among the two main classes of tethering factors one class is the oligomeric complexes such as conserved oligomeric Golgi (COG) complex and Exocysts that bind to SNARES and act as $\mathrm{RAB}$ effectors or oligomeric complexes such as transport protein particle I and II (TRAPP I and TRAPP II) complexes that act as GEFs for Rabs. The other class of coiled-coil tethering factors that function as Rab effectors or Rab GEFs (Eckardt, 2008; Sztul and Lupashin, 2009; Thellmann et al., 2010; Khan et al., 2013). A bioinformatics study predicted several tethering factors to exist in Arabidopsis chloroplast, e.g., COG complexes, Exocysts, and AtCASP that could be dual localized having role in CPOII mediated transport but no homologs for TRAPP complexes were found in the chloroplast (Khan et al., 2013).

\section{ORIGINS OF THE CHLOROPLAST VESICLE TRANSPORT SYSTEM}

A vesicle transport system may also be present in cyanobacteria, since photosynthetic membrane-bound vesicles (Nevo et al., 2007) and vesicle-like structures between their well separated plasma membrane and thylakoids (Schneider et al., 2007) have been observed in TEM images. Furthermore, Tvp38 a SNAREassociated protein with predicted chloroplast localization (Khan et al., 2013), is conserved in chloroplasts and cyanobacteria (Keller and Schneider, 2013), and several of the proteins with suggested involvement in chloroplast vesicle transport are also present in cyanobacteria. Thus, as plant chloroplasts are believed to have arisen from bacterial endosymbiosis related to cyanobacteria engulfed by a eukaryotic cell (Palmer, 2000). Interestingly, VIPP1, responsible for vesicle formation, has been identified in both cyanobacteria and Arabidopsis, which suggests that vesicle transport in chloroplasts originated from a prokaryotic origin such as cyanobacteria, and thus vesicle transport systems could have existed in cyanobacteria before embryophytes emerged (Westphal et al., 2001a).

However, similarities with the cytosolic system suggest that the chloroplast transport machinery has eukaryotic origins, possibly via transfer of components of the secretory pathway to the chloroplast followed by divergent evolution (Vothknecht and Soll,
2005). Analysis of organisms from diverse lineages has revealed that vesicle transport in chloroplasts only occurs in embryophytes, indicating late evolutionary acquisition by land plants (Westphal et al., 2003). This may reflect intense selective pressure to evolve sophisticated systems for constructing, maintaining, and modulating more complex thylakoids following the transition from an aqueous to a non-aqueous environment.

It is possible that some proteins involved in chloroplast vesicle transport have eukaryotic origins while others are prokaryotic. Their roles in chloroplast vesicle transport have not been clearly established, but the latter could have been integrated with a vesicle system transferred from the cytosol to replace existing eukaryotic equivalents. Proteins with no functional homologs in evolving chloroplasts may have been imported from the cytosol, while prokaryotic proteins capable of substituting for cytosolic proteins may have been functionally modified.

\section{SUPPORT FOR A VESICLE TRANSPORT SYSTEMS IN CHLOROPLASTS}

Plant chloroplasts are surrounded by two lipid-bilayer membranes (the outer and inner envelopes) separated by an intermembrane space. The stroma, the main aqueous compartment of the organelle, contains stacks of thylakoids, sites of photosynthesis. Thylakoids are lipid bilayers with a unique glycerolipid composition and significant proportions of both embedded and peripheral multi-protein complexes. They are composed primarily of phospholipids and galactolipids; mono-, and digalactosyldiacylglycerol represent $\sim 50$ and $\sim 25 \mathrm{~mol} \%$ of the total thylakoid lipids, respectively (Douce and Joyard, 1990). Thylakoids are unable to synthesize these compounds. Instead they are produced through a complex pathway involving exchange of lipid precursors between the ER and the inner envelope. Therefore, as the final production site (the inner envelope membrane) and destination (thylakoid) membrane are separated by an aqueous stroma, a specific transport system for these highly hydrophobic compounds is presumably required. Several theories have emerged to explain the transport of hydrophobic compounds to the thylakoids, including lipid transfer at sites of physical contact, diffusion of monomers facilitated by lipid transfer proteins and a vesicular mechanism. However, while there is no evidence for sites of physical contact or lipid transfer proteins, ultrastructural and biochemical studies corroborate the "vesicle theory" (Andersson and Sandelius, 2004).

Vesicle-like structures in plastids were observed in early TEM studies under certain conditions (Muehlethaler and FreyWyssling, 1959; von Wettstein, 1959). These structures appear in the stroma between the chloroplast envelope and thylakoid after low temperature incubation of leaf tissues (Morré et al., 1991b; Westphal et al., 2001b, 2003). Thin serial TEM sections demonstrate that the accumulated vesicles are not tubular extensions from the inner envelope but membrane-enclosed sacs with estimated diameters of 30-70 nm (Westphal et al., 2001b). Vesicles attached to the inner envelope membrane and the thylakoid can also be observed, suggesting the occurrence of fission and fusion events. The appearance of vesicles solely at low temperature $\left(4^{\circ} \mathrm{C}\right)$ suggests that they could be artifacts generated, for instance, when preparing samples for TEM examination. However, analyses of isolated chloroplasts incubated with radiolabeled lipid precursors 
have shown that galactolipid synthesis in vitro is also temperaturedependent. Furthermore, radiolabeling is detectable in lipids in the inner envelope before it appears in thylakoid membranes, strongly indicating that lipids synthesized in the chloroplast envelope are transported to the thylakoid (Andersson et al., 2001). These observations suggest that synthesis and transport of galactolipids, as well as the associated vesicle fission and fusion, can only be observed with current techniques at low temperature because they are too rapid at normal growth temperatures. The cytosolic vesicle transport system between the ER and the Golgi apparatus in mammalian cells can also be blocked by exposure to low temperature, suggesting a certain analogy between the two systems (Moreau et al., 1992).

In support of this analogy, inhibitors of vesicle transport via the secretory pathway have similar inhibitory effects on chloroplast vesicle formation, as demonstrated by the following observations (Westphal et al., 2001b). Addition of o-GTP, GTP $\gamma$ S, and GMP/PNP, which are non-hydrolysable nucleotide analogs, results in nearly complete loss of vesicle accumulation in isolated chloroplasts incubated at $4^{\circ} \mathrm{C}$, and $\mathrm{AlF}_{4}^{-}$ (an inhibitor of GTP-binding proteins) is even more strongly inhibitory. This indicates that vesicle budding is controlled via a GTPase, as in the cytosolic vesicle system where several GTPases are involved in distinct steps of vesicle transport.

The addition of microcystin LR, which impairs membrane fusion in vacuole formation by inhibiting protein phosphatase 1, induces accumulation of vesicles in isolated chloroplasts, suggesting that a protein phosphatase might also be involved in their fusion. Ophiobolin A, an inhibitor of calmodulin, and W7, a $\mathrm{Ca}^{2+}$ antagonist, can also inhibit fusion of vesicles with the acceptor membrane (Westphal etal., 2001b). This is a further similarity, as $\mathrm{Ca}^{2+}$ and calmodulin participate in membrane fusion in the secretory pathway (Peters and Mayer, 1998; Mayer, 1999). Furthermore, investigations using a cellfree system prepared from isolated chloroplasts have revealed requirements for stromal proteins and ATP for transport of lipids to thylakoids, and for stromal proteins, ATP and GTP for their release from isolated envelopes. Their release is also stimulated by acyl-CoA (Morré etal., 1991a; Räntfors etal., 2000).

Collectively, these observations strongly suggest the presence of a protein-mediated vesicle transport system in chloroplasts with basic components similar to those of cytosolic vesicle transport systems.

\section{EXPERIMENTALLY IDENTIFIED MOLECULAR COMPONENTS OF CHLOROPLAST VESICLE TRANSPORT}

If the putative chloroplast vesicle transport system is related to cytosolic systems there is probably some conservation of components between them (Andersson and Sandelius, 2004). Accordingly, using the Arabidopsis genome and web-based localization prediction tools chloroplast-localized proteins with high sequence similarity to components of cytosolic systems have been identified, including eight putative COPII-related vesicle transport proteins (Andersson and Sandelius, 2004). A recent bioinformatics study confirmed the previously reported COPII-related proteins, mainly involved in the initiation and budding stages, and identified several further putative components, e.g., SNAREs, Rabs, tethering factors, and reticulons that could collectively form a complete vesicle transport system in chloroplasts (Khan et al., 2013). Interestingly, two putative components identified in bioinformatics analyses (Andersson and Sandelius, 2004; Khan et al., 2013) have been confirmed to be chloroplast localized, and like the homologous cytosolic vesicle components shown to be active GTPases: CPSAR1 (Figure 1) and CPRabA5e (CP, chloroplast localized) (Table 1; Garcia etal., 2010; Karim et al., 2014). The following sections discuss possible roles of these and several other potentially important players in chloroplast vesicle transport.

\section{GTPases}

\section{Small GTPase CPRabA5e}

As discussed above, small GTPase Rab proteins regulate almost all cytosolic membrane trafficking steps, from the budding of transport vesicles at the donor membrane to their fusion with the target membrane. In their regulatory cycle Rabs select cargo, promote vesicle movement to specific membranes and verify the correct site of fusion via interactions with diverse effector proteins. Rabs generally have a characteristic GTPase fold, composed of a six-stranded $\beta$-sheet flanked by five $\alpha$-helices. The presence of multiple Rabs in the organisms proteome suggests they play specific transport roles in specific pathways (Hutagalung and Novick, 2011; Li et al., 2014). GTPase Rabs have both GTP/GDP binding and GTP hydrolysis capability, allowing them to act as molecular switches: active when GTP-bound and inactive when GDP-bound (Takai et al., 2001; Agarwal etal., 2009). A Rab escort protein (REP) binds newly synthesized Rab proteins and presents them to geranylgeranyl transferase for geranylgeranylation/prenylation at their two C-terminal cysteines, which increases their hydrophobicity, before targeting them to the membrane delivery system (Leung et al., 2006; Schwartz et al., 2007). Prenylated Rabs are stabilized in their inactive, GDP-bearing conformation by binding to the GDP dissociation inhibitor (GDI; Stenmark, 2009; Pfeffer, 2012). The GDI displacement factor (GDF) catalyzes dissociation of Rab-GDI complexes, thereby facilitating association of the Rabs with appropriate membranes. At their respective target membranes Rabs are activated by binding GTP with the assistance of a GEF. Upon completion of a transport cycle GTP hydrolysis is triggered by GAPs, returning the Rabs to an inactive GDP-bound state, which again is maintained by GDI until a new transport cycle is initiated by their recruitment to a membrane (Ali and Seabra, 2005; Nielsen et al., 2008; Stenmark, 2009).

CPRabA5e (Figure 2 and Table 1), one of the recently identified chloroplast-localized Rab GTPases in Arabidopsis (detected by immunoblotting in both the stroma and thylakoids; Karim et al., 2014), is a close homolog of Ypt31/32 GTPases in yeasts. These proteins are involved in trans Golgi trafficking and required for recycling proteins (such as work together with effector Rcyl for recycling of vSNARE Snc1 in yeast) from the plasma membrane through early endosomes to the Golgi complexes (Chen et al., 2011); putatively participate in the yeast exocytic pathway; and apparently involved in both Golgi-to-plasma membrane and endosome-to-Golgi transport (Jedd et al., 1997; Zou et al., 2012). 
Table 1 | Chloroplast localized proteins putatively involved in chloroplast vesicle transport.

\begin{tabular}{|c|c|c|c|c|c|}
\hline Protein, AGI No. & $\begin{array}{l}\text { Chloroplast } \\
\text { localization }\end{array}$ & $\begin{array}{l}\text { Mutant } \\
\text { phenotype }\end{array}$ & Chloroplast phenotype & Domain structures & Reference \\
\hline CPSAR1, At5g18570 & $\begin{array}{l}\text { IEM }^{1}, \text { stroma, } \\
\text { vesicles }\end{array}$ & $\begin{array}{l}\text { Embryo-lethal, } \\
\text { non-viable }\end{array}$ & $\begin{array}{l}\text { Absence of thylakoid } \\
\text { membranes, presence of } \\
\text { stromal vesicles }\end{array}$ & $\begin{array}{l}\mathrm{TP}^{2} \text {, coiled-coil } \\
\text { domain, GTPase } \\
\text { domain }\end{array}$ & $\begin{array}{l}\text { Bang etal. (2009), Chigri } \\
\text { etal. (2009), Garcia etal. } \\
\text { (2010) }\end{array}$ \\
\hline CPRabA5e, At1g05810 & Stroma, thylakoid & $\begin{array}{l}\text { No visible } \\
\text { phenotype }\end{array}$ & $\begin{array}{l}\text { Altered thylakoid development } \\
\text { and organization, increased } \\
\text { presence of stromal vesicles }\end{array}$ & $\begin{array}{l}\text { TP2, GTPase } \\
\text { domain, } \\
\text { geranylgeranylation } \\
\text { motif, unique } \\
\text { YYRGA motif }\end{array}$ & Karim etal. (2014) \\
\hline THF1, At2g20890 & $\begin{array}{l}\text { Envelope, } \\
\text { stroma, thylakoid }\end{array}$ & $\begin{array}{l}\text { Variegated leaves, } \\
\text { delayed } \\
\text { development }\end{array}$ & $\begin{array}{l}\text { Normal green sectors in the } \\
\text { chloroplast, but absence of } \\
\text { thylakoid membranes and } \\
\text { presence of stromal vesicles in } \\
\text { white sectors }\end{array}$ & $\begin{array}{l}\mathrm{TP}^{2}, \text { coiled-coil } \\
\text { domain }\end{array}$ & $\begin{array}{l}\text { Wang etal. (2004), } \\
\text { Huang et al. (2006) }\end{array}$ \\
\hline VIPP1, At1g65260 & $\mathrm{IEM}^{1}$, thylakoid & $\begin{array}{l}\text { Pale-green } \\
\text { leaves, deficient } \\
\text { photosynthesis }\end{array}$ & $\begin{array}{l}\text { Balloon like structure, absence } \\
\text { of thylakoid membranes, } \\
\text { presence of stromal vesicles }\end{array}$ & $\begin{array}{l}\mathrm{TP}^{2}, \alpha \text {-helical } \\
\text { domain, plant } \\
\text { specific C-terminal } \\
\text { domain }\end{array}$ & $\begin{array}{l}\text { Kroll etal. (2001), Aseeva } \\
\text { etal. (2007), Zhang et al. } \\
\text { (2012), Otters et al. (2013) }\end{array}$ \\
\hline FZL, At1g03160 & IEM $^{1}$, thylakoid & $\begin{array}{l}\text { Pale-green } \\
\text { leaves, delayed } \\
\text { development }\end{array}$ & $\begin{array}{l}\text { Fewer and larger chloroplasts, } \\
\text { disorganized thylakoid array, } \\
\text { fewer stroma thylakoids }\end{array}$ & $\begin{array}{l}\mathrm{TP}^{2} \text {, coiled-coil } \\
\text { domain, GTPase } \\
\text { domain, } \mathrm{TM}^{3} \\
\text { domain }\end{array}$ & Gao et al. (2006) \\
\hline $\begin{array}{l}\text { SCO2/CYO1, } \\
\text { At3g19220 }\end{array}$ & Thylakoid & $\begin{array}{l}\text { Pale green/albino } \\
\text { cotyledon }\end{array}$ & $\begin{array}{l}\text { Vesicles emerged from IEM }{ }^{1} \\
\text { mainly at rounded ends of } \\
\text { elongated chloroplasts of } \\
\text { embryonic leaves }\end{array}$ & Zn-finger domain & $\begin{array}{l}\text { Shimada et al. (2007), } \\
\text { Muranaka etal. (2012), } \\
\text { Tanz etal. (2012) }\end{array}$ \\
\hline $\begin{array}{l}\text { CURT1 (A-D), } \\
\text { At4g01150, At2g46820, } \\
\text { At1g52220, At4g38100 }\end{array}$ & Thylakoid & $\begin{array}{l}\text { No visible } \\
\text { phenotype }\end{array}$ & $\begin{array}{l}\text { Flat lobe-like thylakoids with } \\
\text { fewer grana margins }\end{array}$ & $\begin{array}{l}\mathrm{TP}^{2}, \text { two } \mathrm{TM}^{3} \\
\text { domains }\end{array}$ & Armbruster etal. (2013) \\
\hline
\end{tabular}

1 Inner envelope membrane.

2 Transit peptide.

${ }^{3}$ Transmembrane.

The Ypt31p/32p pathway may also regulate putative phospholipid translocases that promote formation of vesicles destined for the TGN, and are thought to be involved in the generation of phospholipid asymmetry in membrane bilayers (Furuta et al., 2007). CPRabA5e restores growth of $y p t 31 \Delta y p t 32^{t s}$ mutants at $37^{\circ} \mathrm{C}$ in yeast complementation studies, strongly supporting the bioinformatic indications that CPRabA5e participates in vesicle transport. In addition, seed germination is delayed and under oxidative stress growth is arrested in cprabA5e knockout mutants, chloroplasts contain larger plastoglobules, thinner grana, and more vesicles close to the envelopes than wild type counterparts (Table 1). A yeast-two-hybrid screen with CPRabA5e as bait revealed 13 interacting proteins, mainly located in thylakoids and plastoglobules. These proteins have known or predicted involvement in development, stress responses, and photosynthesis related processes, consistent with the observed stress phenotypes. They include curvature thylakoid 1A (CURT1A), one of a set of four CURT1 and proteins (A-D) that are conserved in plants and cyanobacteria, highly concentrated at grana margins of thylakoids (Figure 2 and Table 1). In a recent work it has been shown elaborately that the CURT1 proteins (A-D) as a family cluster form oligomers, control the membrane curvature, determine the architecture of grana and control grana formation in Arabidopsis (Armbruster et al., 2013). Interestingly, in double, triple, and quadruple loss of function mutants of CURT1 (A-D) thylakoids were occasionally wider and curved, lacking grana stacks and accumulating vesicles, suggesting a role of theses vesicles in thylakoid formation (Armbruster et al., 2013; Luque and Ochoa de Alda, 2014). However, both curtla single mutant and cprabA5e mutant chloroplasts reportedly have thin 
grana, supporting the notion that CPRabA5e is involved in processes that control thylakoid morphology (Armbruster et al., 2013; Karim et al., 2014).

In addition, two other putatively chloroplast-localized Rab proteins have been identified, RabB1c and RabF1. The latter (also known as ARA6 in Arabidopsis, or RAB5 according to human Rab nomenclature) is unique to plants, and reportedly involved in endosomal transport and modulation of the assembly of SNARErelated complexes (Ebine et al., 2011, 2012). Preliminary data obtained using an ARA6/RabF1 specific antibody have verified the presence of CPRabF1 in both the envelope and thylakoids of chloroplasts, implying that it has dual localization (Alezzawi, 2014). However, the precise role of CPRabF1 in vesicle transport in chloroplasts requires further elucidation. CPRabF1's localization in the envelope and thylakoid membranes could indicate that CPRabF1 (ARA6) in the vicinity of the donor (envelope/thylakoid) and acceptor (envelope/thylakoid) membranes might modulate assembly of SNARE complexes in chloroplasts (Ebine et al., 2011, 2012). However, further verifications of this hypothesis are required.

\section{GTPase CPSAR1}

CPSAR1 (Figures 1 and 2; Table 1) is suggested to be a homolog of Sar1, which is essential for assembly of the COPII coat. It has GTPase activity, plays a role in thylakoid biogenesis, and is present both at the inner envelope and in the stroma (compatible with a function in vesicle initiation), but also around cold-induced vesicles (Figure 1; Garcia et al., 2010). Several GTPases, including the cytosolic Arf1 and Sar1, have dual distributions being located at donor membranes when GTP-bound and soluble following GTP hydrolysis (Figure 2). Moreover, cpsar1 knockout in Arabidopsis causes severe disorders, including embryo lethality and absence of thylakoids in embryos, signifying a role in thylakoid biogenesis (Table 1). CPSAR1 is a member of the Obg (Spo0B-associated GTP-binding protein) subfamily, which has suggested involvement in various processes, including chromosome partitioning, ribosome functions, sporulation, and stress responses (Kobayashi et al., 2001). Accordingly, CPSAR1 has proposed roles in ribosome biogenesis involving chloroplast-encoded subunits, and thus has also been named ObgC (Bang et al., 2009, 2012). Thus, there is evidence for two distinct roles of CPSAR1. However, the presence of CPSAR1 in envelopes and vesicles, but not close to the thylakoids where ribosomes are closely located, indicates that it is functionally involved in vesicle transport (Marin-Navarro et al., 2007).

\section{Large GTPase dynamins}

Dynamins comprise a large superfamily of GTPases with five characteristic domains. Dynamins are involved in many cellular processes, inter alia division of chloroplasts, peroxisomes and mitochondria. They also participate, in concert with clathrin assembly and membrane-remodeling proteins, in the invagination of clathrin-coated buds and vesiculation during clathrin-mediated endocytosis (CME), which plays various critical roles in plant development. Dynamin-related proteins (DRP) differ from classical dynamins, but share at least three of the five characteristic domains; the GTPase, middle, and GTPase-effector domain (GED;
Heymann and Hinshaw, 2009). In plants there are two main families of DRPs, both of which apparently participate in clathrinmediated transport, DRP1 and DRP2. The Arabidopsis genome encodes 16 DRPs, grouped into six subfamilies (DRP1-DRP6) based on their amino acid sequences and predicted domains (Backues etal., 2010; Bednarek and Backues, 2010). DRP 5B, DRP5B/ARC5 (accumulation and replication of chloroplasts 5) is a functional GTPase, essential for the division of chloroplasts in plants and localized at the outer envelope of chloroplasts. DRP5B/ARC5 has two functional isoforms and plastid division proteins 1 and 2 (PDV1 and PDV2) interact with DRP5B/ARC5 and regulate its GTPase activity (Gao et al., 2013; Holtsmark et al., 2013).

Several functional analogs of dynamins such as a filamentous temperature sensitive $\mathrm{z}$ protein, FtsZs (tubulin-like GTPases) play essential roles in the division of prokaryotic and eukaryotic cells, chloroplasts, and mitochondria. In plants, stromal FtsZ ring (Z-ring) formation initiates the division process. Arabidopsis harbors three FtsZ genes: FtsZ1, FtsZ2-1 (which are functionally redundant; Schmitz et al., 2009) and FtsZ2-2. The Z-rings of FtsZs can spontaneously self-assemble and interact with each other (El-Kafafi etal., 2008; Gargano etal., 2013). FZO is a dynamin-related membrane-remodeling protein that mediates fusion between mitochondrial outer membranes in animals and fungi. A single FZO-like protein in Arabidopsis, FZL, is regarded as a plant-specific member of the dynamin superfamily associated with the thylakoid and envelope membranes (Figure 2 and Table 1). Fzl mutants have abnormalities in both morphology and the distribution of granal and stromal thylakoids (Table 1). In $f z l$ mutant chloroplasts grana lamellae are less uniform in shape and inflated at their margins, resulting in a disorganized thylakoid structure and accumulation of vesicles, indicating that theses vesicles have a role in thylakoid morphology (Gao et al., 2006). FtsZ1 and FZL, which are involved in plastid division, participate in remodeling of thylakoid membranes and are not involved in early steps of thylakoid biogenesis. FtsZ phosphorylation affects GTPase activity,

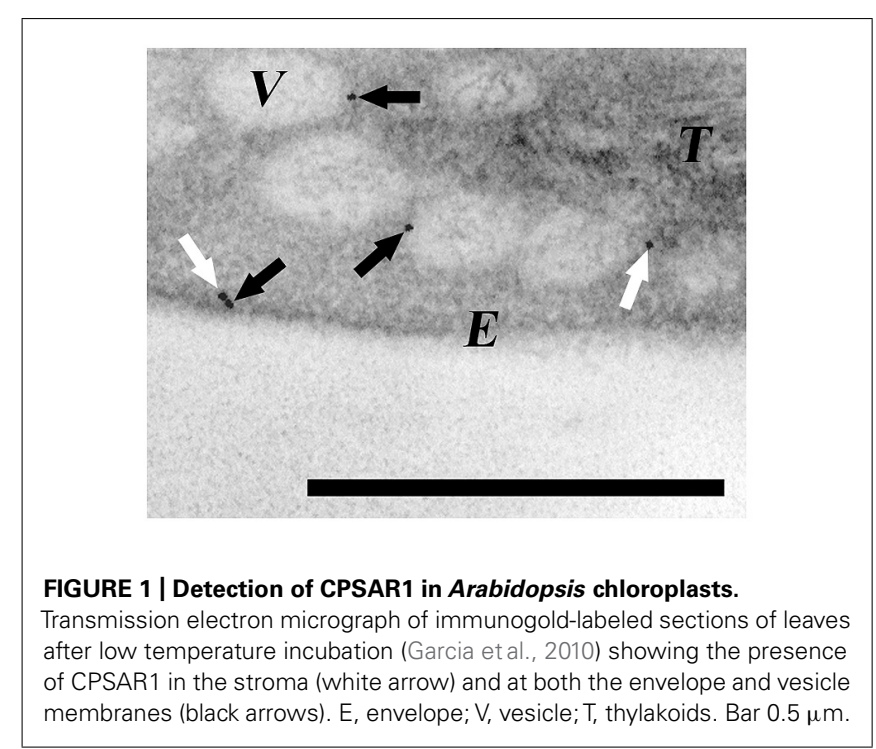


OUTSIDE OF THE CHLOROPLAST

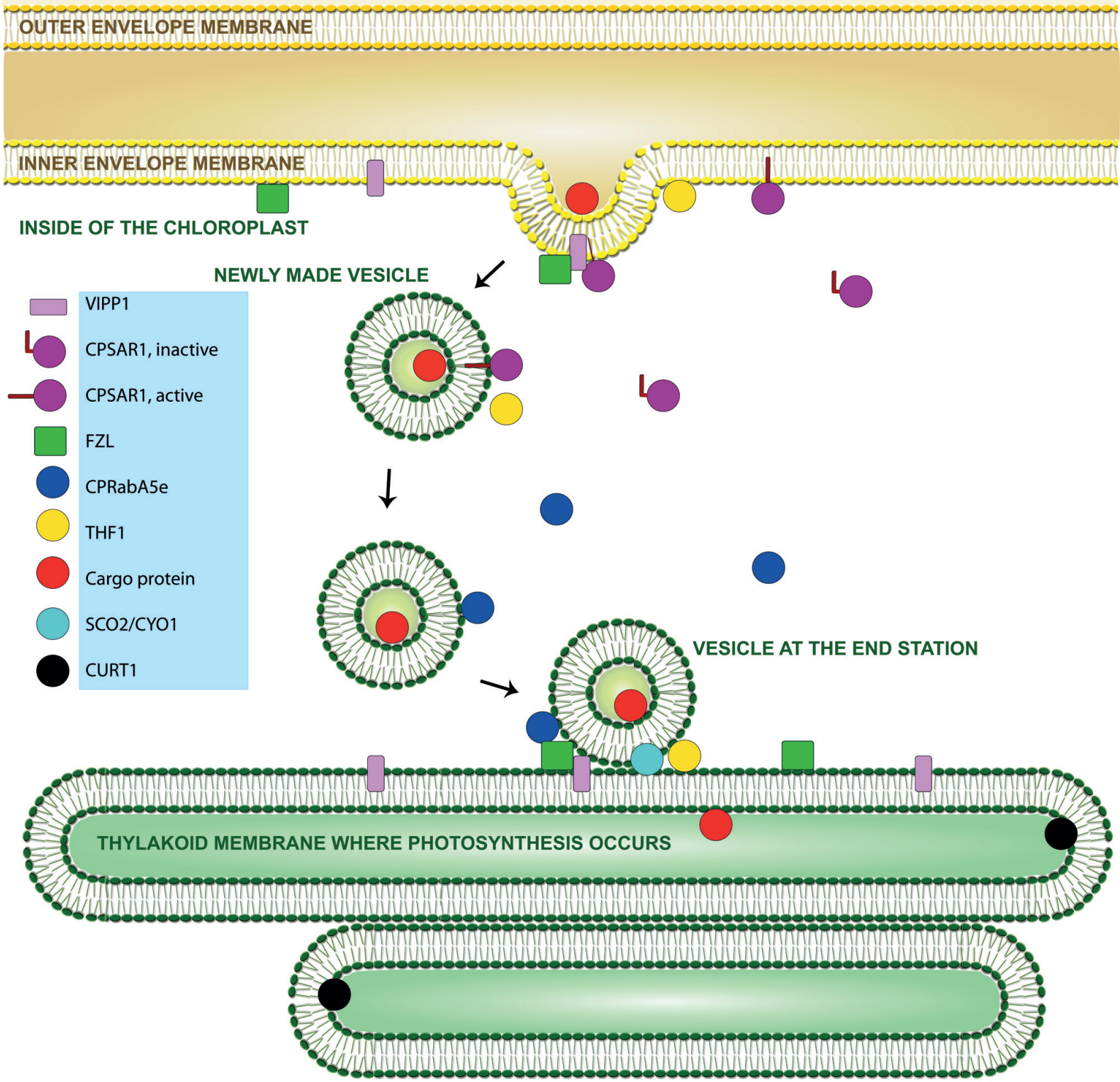

FIGURE 2 | Schematic diagram of vesicle formation and movement in chloroplasts. Proteins included are those with suggested involvement in chloroplast vesicle transport, and verified to be chloroplast localized. VIPP1 (pink), FZL (green), and THF1 (yellow) are located both at the donor membrane (inner envelope) and the acceptor membrane (thylakoids), and could thus participate in both fission and fusion of vesicles. CPSAR1 (violet) is located at the donor membrane, the vesicle and in the stroma, indicating that it plays a similar role as the cytosolic Sar1, i.e., in an active GTP-bound state it helps to form vesicles, and in an inactive GDP-bound state it is recycled back to the donor membrane for a subsequent cycle. THF1 (yellow) and CPRabA5e (blue) are both located in the stroma and the acceptor membrane (thylakoids) may interact with the vesicle just prior to fusion and facilitating this step. SCO2/CYO1 (turquoise) and CURT1 (black) are located at the acceptor membrane and may interact with vesicles for the transport of molecules, e.g., cargo protein(s; red) and facilitating the fusion (delivery) step. polymerization, and interactions with other division proteins. Interestingly, AtFtsZ2 is phosphorylated in vivo and it has been suggested that an interacting partner of AtFtsZ2, phosphoglycerate kinase 1 (PGK1), might be responsible for FtsZ phosphorylation. This phosphorylation may play a regulatory role in plastid division
(Gargano et al., 2012). PGK1 is reportedly an interacting partner of CPRabA5e, but it is unclear whether CPRabA5e participates in PGK1 regulation. If so, chloroplast-localized Rabs could be linked to plastid division through remodeling of the thylakoid membranes. However, in cprabA5e mutants the granal stacks 
are reportedly appressed to thylakoid membranes (Karim et al., 2014).

Dynamin-related proteins ADL1A/DRP1A and ADL2A/DRP3A (role in both peroxisomal and mitochondrial division; Zhang and $\mathrm{Hu}, 2010)$ in Arabidopsis appear to be similar to the animal dynamin I protein, both subfamilies seems to be unique to plants (Park et al., 1997; Kang et al., 2003; Fujimoto et al., 2010). Analysis of Arabidopsis adl1A mutants showed ADL1A to be vital role for embryogenesis, seedling development, reproduction, formation of Golgi stacks and accumulation of secretory vesicles close to the plasma membrane (Park et al., 1997). In absence of ADL1A abnormal accumulation of plasma membrane possibly disrupts targeting and fusion of exocytotic vesicles to the cell surface as a result disruption of cell wall biosynthesis occurs (Kang et al., 2003). Arabidopsis ADL1A deletion mutants showed yellow leaf phenotype with reduced number of chloroplast, not morphologically developed with reduced amount of thylakoid membranes. In earlier reports the localization of ADL1A in thylakoid membranes in suborganellar fractionation suggested ADL1A to have a role in vesicle formation as a dynamin protein in chloroplasts (Park et al., 1998). However, in contradiction a later study including subcellular fractionation and immunolocalization results obtained by using the ADL1A-specific antibody established that ADL1A is targeted to the cell plate during cytokinesis and not being associated with chloroplasts (Kang et al., 2001). Moreover, using GFP fusion proteins it was also observed that the ADL2A was localized in mitochondria but not in chloroplasts (Arimura et al., 2004). Therefore it raises doubts whether or not ADL1A and/or ADL2A are CP localized.

\section{OTHER IMPORTANT FACTORS FOR CHLOROPLAST VESICLE TRANSPORT Vesicle-inducing protein in plastids 1 (VIPP1)}

The Arabidopsis vesicle-inducing protein in plastids 1 (VIPP1) is localized in the inner envelope and the thylakoid membranes even though VIPP1 is a hydrophilic protein (Figure 2 and Table 1). In chloroplasts of vipp1 deletion mutant vesicle formation is abolished, thus it results in inhibition of thylakoid formation (Kroll et al., 2001). VIPP1 is closely related to the phage shock protein A (PspA) in Escherichia coli, a protein induced under diverse stress conditions. In addition, VIPP1 possesses an additional plant specific C-terminal domain, suggested to be required for its role in thylakoid biogenesis (Aseeva et al., 2004). VIPP1 retains $\alpha$-helical domain same as in PspA, which is essential for the association of VIPP1 to the inner envelope membrane (Otters et al., 2013). However, VIPP1 is essential for both thylakoid formation and for the maintenance of chloroplast envelopes. The knockout mutant of VIPP1 is lethal but knock-down or partial mutant plants with a reduced amount of VIPP1 showed variegated leaves (pale-green) and cotyledons, whereas young seedlings of knockout mutants can only survive on MS medium showing albino morphology. Knock-down plants showed decrease in thylakoid membrane content, but thylakoid membranes are assembled with thylakoid protein complexes being photosynthetically active. It suggests that VIPP1 is required for basic thylakoid membrane formation but not being involved in the content of thylakoid protein complexes (Westphal etal., 2001a; Aseeva et al., 2007; Vothknecht et al., 2012; Zhang et al., 2012). VIPP1 has also been suggested to be involved in protein translocation by enhancing protein transport through the twin-arginine translocation (Tat) pathway (Lo and Theg, 2012). Moreover, the vipp1 knockdown and knockout plants show balloon-like structures in chloroplasts, a rather unique morphology. All vippl knockout mutant plastids demonstrated balloon-like chloroplasts without any green area (thylakoid membranes) whereas in knockdown plants many of the chloroplasts show balloon-like structures containing thylakoids in a limited area of the chloroplasts (Zhang et al., 2012).

\section{Thylakoid formation 1 (THF1)}

An Arabidopsis thylakoid formation1 (THF1) protein is found to be localized in the envelope, thylakoid membrane and stroma of chloroplasts (Figure 2 and Table 1; Wang et al., 2004; Huang et al., 2006). THF1 was suggested to be involved in the process of organization of transport vesicles into mature thylakoid stacks. The thf 1 mutant showed variegation (pale green cotyledons) phenotype in both cotyledons and leaves, slower growth rates, defects in etioplast development in darkness, increased sensitivity to high light, lower PSII efficiency, and stay-green phenotype in stress-induced leaves (Wang et al., 2004; Keren et al., 2005; Wu et al., 2011; Huang et al., 2013; Gan et al., 2014). Plastids of pale/non green sectors of variegated leaves of $t h f 1$, which are suggested to be light independent, accumulate membrane vesicles and lack organized thylakoid structures, suggesting that THF1 plays a vital role in a process of vesicle-mediated thylakoid membrane biogenesis (Wang et al., 2004; Wu et al., 2011). THF1 was found to be controlling photosystem II-light-harvesting complexes (PSII-LHCII) dynamics during dark induced senescence and light acclimation. It interacts with the light-harvesting chlorophyll a/b binding protein LHCB in a $\mathrm{pH}$ dependent manner, and the stay-green phenotype of thf1 relies on the presence of LHCII complexes (Huang et al., 2013). In etioplasts of dark-grown cotyledons of thf1 mutants ultrastructural analysis identified coexistence of plastids with different developmental stages of prolamellar bodies (PLB), i.e., from normal developed to almost no PLB developed, and chlorophyll biosynthesis and expression of several plastidic genes were suppressed in thfl (Wu et al., 2011). Interestingly, the THF1 ortholog in rice is suggested to be involved in the degradation of chlorophyll (Yamatani et al., 2013). In addition, THF1 protein has also been proposed to have a role in sugar signaling in Arabidopsis through the interaction with a heteromeric G-protein GPA1 (Huang et al., 2006).

\section{Snowy cotyledon 2/cotyledon chloroplast biogenesis factor (SC02/CY01)}

An Arabidopsis disulfide isomerase located in thylakoids (Figure 2 and Table 1), SCO2/CYO1, caused specifically disruption of chloroplast biogenesis in cotyledons in sco2/cyol mutants. The sco $2 /$ cyo 1 mutants showed pale green/albino cotyledon but turned into normal green true leaves during development (Shimada et al., 2007; Albrecht et al., 2008; Muranaka et al., 2012; Tanz et al., 2012). chloroplasts ultrastructure observed in sco2/cyol cotyledons were either of normal shape or were globular with large vesicles emerged from the inner envelope mainly at the rounded ends of the elongated chloroplasts, not observed in wild-type chloroplasts. Loss of SCO2/CYO1 might interrupt the functions of vesicles formation for thylakoid membranes in embryonic leaves and as a result 
accumulation of these vesicles was apparent at the rounded ends of the sco2/cyo1 chloroplasts (Tanz et al., 2012). These vesicles were involved in the integration of the photosystem proteins into thylakoids including LHCB. SCO2/CYO1 was found to be interacting with the protein subunits of PSI and PSII (Muranaka et al., 2012; Tanz etal., 2012). It was observed that LHCB1 interacted with SCO2/CYO1 thus, SCO2/CYO1 might be involved in integration of LHCB1 proteins into thylakoids. Interestingly, this suggests that the lack of interaction of SCO2/CYO1 with LHCB1 in sco2/cyo 1 mutants results in inhibiting integration of $\mathrm{LHCB}$, delaying the merging of vesicles into thylakoid membranes and thus vesicles being accumulated in chloroplasts (Tanz et al., 2012).

\section{VESICLE TRANSPORT OF CARGO PROTEINS IN CHLOROPLASTS}

An intriguing question is whether proteins are also transported in vesicles to the thylakoids in addition to lipids (Figure 2). No cargo proteins have been definitively identified, but downregulation of several nuclear-encoded photosynthetic proteins has been observed in obgc-1 (cpsar1) RNAi mutants (Bang et al., 2012), indicating that they are potential cargos. Furthermore, recent studies using the sco2/cyo 1 mutant indicate that LHCB1 is a potential cargo (Tanz et al., 2012). However, SCO2/CYO1 interacts directly with LHCB1, but not with the components of the signal recognition particle (SRP) pathway that normally targets LHCB1 to the thylakoids. Moreover, the suggested pathway for LHCBs would mainly occur in the cotyledon stage and be less significant for mature plants (Tanz etal., 2012). This is consistent with the reported embryo lethality of cpsar1 mutation (Bang et al., 2009; Chigri et al., 2009; Garcia et al., 2010) and the coloration of obgc-1 (cpsar1) RNAi mutant leaves (pale green when young, but wild-type like in later developmental stages; Bang et al., 2012). If LHCBs are cargo proteins several more may be present, including (potentially) at least some of the LHCB member proteins that interact with CPRabA5e (Karim et al., 2014). Bioinformatics searches for homologs to thylakoid-located proteins with a COPII cargo selection motif have identified several candidates, including 21 putative transmembrane cargos and 12 putative soluble cargos (Khan et al., 2013). Interestingly, 45\% of these potential cargo proteins are linked to photosynthesis, indicating that some nuclear-encoded proteins may be targeted to thylakoids via vesicles (in addition to the four other known targeting mechanisms; Spetea and Aronsson, 2012). Moreover, some of the putative transmembrane cargo proteins were LHCBs (Khan et al., 2013).

\section{IS THERE A COPII, COPI, OR CCV TRANSPORT SYSTEM INSIDE CHLOROPLAST?}

If CPSAR1 is involved in vesicle transport in chloroplasts, in accordance with its localization and bioinformatics indications (Garcia et al., 2010; Brandizzi, 2011), homologs of components of other secretory pathways should be present in chloroplasts (unless the chloroplast system radically differs from other vesicle transport systems). Accordingly, some have been identified and the first outcomes were mainly COPII-related components, acting mainly in the vesicle formation stage (Andersson and Sandelius, 2004), but others (including GAPs, GEFs, tethering factors, and SNAREs) were identified in a more recent extended bioinformatics analysis
(Khan et al., 2013). However, recent data (Lindquist et al., 2014) indicate that no system resembling cytosolic CCV or COPI systems is present in Arabidopsis or rice chloroplasts. Several chloroplastic proteins homologous to subunits of typical COPI and CCV systems were identified, but they have already been ascribed with other functions and unrelated to vesicle transport. About 30 chloroplastic proteins were identified in a motif-based homology search, including homologs for four B-COPI coat subunits and one F-COPI coat subunit. Even more CCV-related subunits were identified, including putative clathrin heavy and light chain components, one or more subunits of AP1-5 complexes, and some coat GTPases (Arf-related proteins). However, no homologs of several other essential proteins for a functional COPI or CCV vesicle transport systems were detected. Thus, the presence of a CCVor COPI-like system in chloroplasts seems unlikely (unless, as mentioned, some components radically differ from their cytosolic counterparts). The occurrence of a putative CCV AP2 $\beta 2$ subunit speculatively supports the idea of a unique system, since this subunit is present in yeast, but not in Arabidopsis cytosol. In addition, several of the putative COPI and CCV subunits identified in chloroplasts had greater resemblance to yeast than Arabidopsis counterparts. Thus, further analysis is required to determine definitively if vesicle transport in chloroplasts relies solely on COPII-related proteins, or a distinct system perhaps involving some proteins similar to cytosolic COPI/CCV proteins is present (Khan et al., 2013; Paul et al., 2014). Furthermore, although some proteins, possibly involved in a COPII-related vesicle transport system in chloroplasts, have been identified, their exact functions and localization remain to be clarified (Khan et al., 2013; Paul et al., 2014).

\section{CONCLUDING REMARKS}

Proteins here described as being linked to chloroplast vesicle transport do share similar trends regarding vesicle transport and thylakoid formation and structure. In all chloroplast mutant phenotypes (except VIPP1 being responsible for vesicle initiation) observed vesicle accumulation inside chloroplasts implicate these proteins to have a role in vesicle transport. Moreover, they demonstrate similar role for thylakoid membrane formation and morphology. Thus, recent identification of putative chloroplast localized vesicle transport proteins and the empirical verification of the location and function of few of them provide strong indications that vesicle-based protein transport machinery is present in chloroplasts. However, numerous aspects have not yet been elucidated, notably the precise roles of the CPSAR1 and CPRabA5e GTPases, and other putative participants. Better knowledge of these systems and their actors would help efforts to understand evolutionary aspects of their acquisition by land plants and their roles in both cargo protein transport to the thylakoids and recycling back to or through the membranes. It could also help to elucidate important but poorly understood aspects of chloroplast biogenesis, e.g., thylakoid formation and maintenance, including building of the photosynthetic machinery.

\section{ACKNOWLEDGMENTS}

We thank the Electron Microscopy Unit of Gothenburg University for microscopy studies, and Christel Garcia for help with figures. 
This work was supported by the Olle Engkvist Foundation (Henrik Aronsson and Sazzad Karim).

\section{REFERENCES}

Agarwal, P., Reddy, M., Sopory, S., and Agarwal, P. K. (2009). Plant rabs: characterization, functional diversity, and role in stress tolerance. Plant Mol. Biol. Report 27, 417-430. doi: 10.1007/s11105-009-0100-9

Albrecht, V., Ingenfeld, A., and Apel, K. (2008). Snowy cotyledon 2: the identification of a zinc finger domain protein essential for chloroplast development in cotyledons but not in true leaves. Plant Mol. Biol. 66, 599-608. doi: 10.1007/s11103-008-9291-y

Alezzawi, M. (2014). Vesicle Transport in Chloroplasts with Emphasis on Rab Proteins. Ph.D. thesis, University of Gothenburg, Sweden.

Ali, B., and Seabra, M. (2005). Targeting of Rab GTPases to cellular membranes. Biochem. Soc. Trans. 33, 652-656. doi: 10.1042/BST0330652

Andersson, M. X., Kjellberg, J. M., and Sandelius, A. S. (2001). Chloroplast biogenesis. Regulation of lipid transport to the thylakoid in chloroplasts isolated from expanding and fully expanded leaves of pea. Plant Physiol. 127, 184-193. doi: 10.1104/pp.127.1.184

Andersson, M. X., and Sandelius, A. S. (2004). A chloroplast-localized vesicular transport system: a bio-informatics approach. BMC Genomics 5:40. doi: 10.1186/1471-2164-5-40

Arimura, S., Aida, G. P., Fujimoto, M., Nakazono, M., and Tsutsumi, N. (2004). Arabidopsis dynamin-like protein 2a (ADL2a), like ADL2b, is involved in plant mitochondrial division. Plant Cell Physiol. 45, 236-242. doi: 10.1093/pcp/pch024

Armbruster, U., Pribil, M., Viola, S., Xu, W., Scharfenberg, M., Hertle, A. P., et al. (2013). Arabidopsis CURVATURE THYLAKOID1 proteins modify thylakoid architecture by inducing membrane curvature. Plant Cell 25, 2661-2678. doi: 10.1105/tpc.113.113118

Aseeva, E., Ossenbühl, F., Eichacker, L. A., Wanner, G., Soll, J., and Vothknecht, U. C. (2004). Complex formation of Vipp1 depends on its $\alpha$-helical PspA-like domain. J. Biol. Chem. 279, 35535-35541. doi: 10.1074/jbc.M401750200

Aseeva, E., Ossenbühl, F., Sippel, C., Cho, W. K., Stein, B., Eichacker, L. A., et al (2007). Vippl is required for basic thylakoid membrane formation but not for the assembly of thylakoid protein complexes. Plant Physiol. Biochem. 45, 119-128. doi: 10.1016/j.plaphy.2007.01.005

Backues, S. K., Korasick, D. A., Heese, A., and Bednarek, S. Y. (2010). The Arabidopsis dynamin-related protein 2 family is essential for gametophyte development. Plant Cell 22, 3218-3231. doi: 10.1105/tpc.110.077727

Bang, W. Y., Chen, J., Jeong, I. S., Kim, S. W., Kim, C. W., Jung, H. S., et al. (2012). Functional characterization of $\mathrm{ObgC}$ in ribosome biogenesis during chloroplast development. Plant J. 71, 122-134. doi: 10.1111/j.1365-313X.2012.04976.x

Bang, W. Y., Hata, A., Jeong, I. S., Umeda, T., Masuda, T., Chen, J., et al. (2009). AtObgC, a plant ortholog of bacterial Obg, is a chloroplast-targeting GTPase essential for early embryogenesis. Plant Mol. Biol. 71, 379-390. doi: 10.1007/s11103-009-9529-3

Barlow, L. D., Dacks, J. B., and Wideman, J. G. (2014). From all to (nearly) none: tracing adaptin evolution in fungi. Cell. Logist. 4:e28114. doi: 10.4161/cl.28114

Barlowe, C., and Schekman, R. (1993). SEC12 encodes a guanine-nucleotideexchange factor essential for transport vesicle budding from the ER. Nature 365, 347-349. doi: 10.1038/365347a0

Bassham, D. C., Brandizzi, F., Otegui, M. S., and Sanderfoot, A. A. (2008). The secretory system of Arabidopsis. Arabidopsis Book 6:e0116. doi: 10.1199/tab.0116

Battey, N. H., James, N. C., Greenland, A. J., and Brownlee, C. (1999). Exocytosis and endocytosis. Plant Cell 11, 643-659. doi: 10.1105/tpc.11.4.643

Bednarek, S., and Backues, S. (2010). Plant dynamin-related protein families DRP1 and DRP2 in plant development. Biochem. Soc. Trans. 38:797. doi: 10.1042/BST0380797

Bethune, J., Wieland, F., and Moelleken, J. (2006). COPI-mediated transport. J. Membr. Biol. 211, 65-79. doi: 10.1007/s00232-006-0859-7

Bharucha, N., Liu, Y., Papanikou, E., McMahon, C., Esaki, M., Jeffrey, P. D., et al. (2013). Sec16 influences transitional ER sites by regulating rather than organizing COPII. Mol. Biol. Cell 24, 3406-3419. doi: 10.1091/mbc.E13-04-0185

Bi, X., Corpina, R. A., and Goldberg, J. (2002). Structure of the Sec23/24-Sar1 pre-budding complex of the COPII vesicle coat. Nature 419, 271-277. doi: 10.1038 /nature 01040

Bonifacino, J. S., and Glick, B. S. (2004). The mechanisms of vesicle budding and fusion. Cell 116, 153-166. doi: 10.1016/S0092-8674(03)01079-1
Brandizzi, F. (2011). Is there a COPII-mediated membrane traffic in chloroplasts? Traffic 12, 9-11. doi: 10.1111/j.1600-0854.2010.01129.x

Chen, S. H., Shah, A. H., and Segev, N. (2011). Ypt31/32 GTPases and their F-Box effector Rcyl regulate ubiquitination of recycling proteins. Cell. Logist. 1, 21-31 doi: 10.4161/cl.1.1.14695

Chigri, F., Sippel, C., Kolb, M., and Vothknecht, U. C. (2009). Arabidopsis OBG-like GTPase (AtOBGL) is localized in chloroplasts and has an essential function in embryo development. Mol. Plant 2, 1373-1383. doi: 10.1093/mp/ssp073

D'Souza-Schorey, C., and Chavrier, P. (2006). ARF proteins: roles in membrane traffic and beyond. Nat. Rev. Mol. Cell Biol. 7, 347-358. doi: 10.1038/nrm1910

De Craene, J.-O., Courte, F., Rinaldi, B., Fitterer, C., Herranz, M. C., SchmittKeichinger, C., et al. (2014). Study of the plant COPII vesicle coat subunits by functional complementation of yeast Saccharomyces cerevisiae mutants. PLoS ONE 9:e90072. doi: 10.1371/journal.pone.0090072

Dingle, J. (1968). Vacuoles, vesicles and lysosomes. Br. Med. Bull. 24, 141-145.

Douce, R., and Joyard, J. (1990). Biochemistry and function of the plastid envelope. Annu. Rev. Cell Biol. 6, 173-216. doi: 10.1146/annurev.cb.06.110190.001133

Ebine, K., Fujimoto, M., Okatani, Y., Nishiyama, T., Goh, T., Ito, E., et al. (2011). A membrane trafficking pathway regulated by the plant-specific RAB GTPase ARA6. Nat. Cell Biol. 13, 853-859. doi: 10.1038/ncb2270

Ebine, K., Miyakawa, N., Fujimoto, M., Uemura, T., Nakano, A., and Ueda, T. (2012). Endosomal trafficking pathway regulated by ARA6, a RAB5 GTPase unique to plants. Small GTPases 3:23. doi: 10.4161/sgtp.18299

Eckardt, N. A. (2008). An exocyst vesicle tethering complex in plants. Plant Cell 20, 1188-1188. doi: 10.1105/tpc.108.200511

El-Kafafi, E., Karamoko, M., Pignot-Paintrand, I., Grunwald, D., Mandaron, P., Lerbs-Mache, S., et al. (2008). Developmentally regulated association of plastid division protein FtsZ1 with thylakoid membranes in Arabidopsis thaliana. Biochem. J. 409, 87-94. doi: 10.1042/BJ20070543

El Kasmi, F., Krause, C., Hiller, U., Stierhof, Y.-D, Mayer, U., Conner, L., et al. (2013). SNARE complexes of different composition jointly mediate membrane fusion in Arabidopsis cytokinesis. Mol. Biol. Cell 24, 1593-1601. doi: 10.1091/mbc.E13-020074

Faini, M., Beck, R., Wieland, F. T., and Briggs, J. A. (2013). Vesicle coats: structure, function, and general principles of assembly. Trends Cell Biol. 23, 279-288. doi: 10.1016/j.tcb.2013.01.005

Fiedler, K., Veit, M., Stamnes, M. A., and Rothman, J. E. (1996). Bimodal interaction of coatomer with the p24 family of putative cargo receptors. Science 273, 13961399. doi: $10.1126 /$ science.273.5280.1396

Fujimoto, M., Arimura, S., Ueda, T., Takanashi, H., Hayashi, Y., Nakano, A., et al. (2010). Arabidopsis dynamin-related proteins DRP2B and DRP1A participate together in clathrin-coated vesicle formation during endocytosis. Proc. Natl. Acad. Sci. U.S.A. 107, 6094-6099. doi: 10.1073/pnas.0913562107

Furuta, N., Fujimura-Kamada, K., Saito, K., Yamamoto, T., and Tanaka, K. (2007). Endocytic recycling in yeast is regulated by putative phospholipid translocases and the Ypt31p/32p-Rcylp pathway. Mol. Biol. Cell 18, 295-312. doi: 10.1091/mbc.E06-05-0461

Gan, Y., Li, H., Xie, Y., Wu, W., Li, M., Wang, X., et al. (2014). THF1 mutations lead to increased basal and wound-induced levels of oxylipins that stimulate anthocyanin biosynthesis via COI1 signaling in Arabidopsis. J. Integr. Plant Biol. doi: 10.1111/jipb.12177 [Epub ahead of print].

Gao, H., Sage, T. L., and Osteryoung, K. W. (2006). FZL, an FZO-like protein in plants, is a determinant of thylakoid and chloroplast morphology. Proc. Natl. Acad. Sci. U.S.A. 103, 6759-6764. doi: 10.1073/pnas.0507287103

Gao, Y., Liu, H., An, C., Shi, Y., Liu, X., Yuan, W., et al. (2013). Arabidopsis FRS4/CPD25 and FHY3/CPD45 work cooperatively to promote the expression of the chloroplast division gene ARC5 and chloroplast division. Plant J. 75, 795-807. doi: 10.1111/tpj.12240

Garcia, C., Khan, N. Z., Nannmark, U., and Aronsson, H. (2010). The chloroplast protein CPSAR1, dually localized in the stroma and the inner envelope membrane, is involved in thylakoid biogenesis. Plant J. 63, 73-85. doi: 10.1111/j.1365-313X.2010.04225.x

Gargano, D., Maple-Grodem, J., and Moller, S. G. (2012) In vivo phosphorylation of FtsZ2 in Arabidopsis thaliana. Biochem. J. 446, 517-521. doi: 10.1042/BJ20120404 Gargano, D., Maple-Grødem, J., Reisinger, V., Eichacker, L. A., and Møller, S. G. (2013). Analysis of the chloroplast proteome in arc mutants and identification of novel protein components associated with FtsZ2. Plant Mol. Biol. 81, 235-244. doi: $10.1007 /$ s11103-012-9994-y 
Grant, B. D., and Donaldson, J. G. (2009). Pathways and mechanisms of endocytic recycling. Nat. Rev. Mol. Cell Biol. 10, 597-608. doi: 10.1038/nrm2755

Harrison, S. C., and Kirchhausen, T. (2010). Conservation in vesicle coats. Nature 466:26. doi: 10.1038/4661048a

Heymann, J. A., and Hinshaw, J. E. (2009). Dynamins at a glance. J. Cell Sci. 122, 3427-3431. doi: 10.1242/jcs.051714

Hirst, J., Barlow, L. D., Francisco, G. C., Sahlender, D. A., Seaman, M. N., Dacks, J. B., et al. (2011). The fifth adaptor protein complex. PLoS Biol. 9:e1001170. doi 10.1371/journal.pbio. 1001170

Hirst, J., Irving, C., and Borner, G. H. (2013). Adaptor protein complexes AP-4 and AP-5: new players in endosomal trafficking and progressive spastic paraplegia. Traffic 14, 153-164. doi: 10.1111/tra.12028

Holtsmark, I., Lee, S., Lunde, K. A., Auestad, K., Maple-Grødem, J., and Møller, S. G. (2013). Plastid division control: the PDV proteins regulate DRP5B dynamin activity. Plant Mol. Biol. 82, 255-266. doi: 10.1007/s11103-013-0059-7

Huang, J., Taylor, J. P., Chen, J.-G., Uhrig, J. F., Schnell, D. J., Nakagawa, T., et al. (2006). The plastid protein THYLAKOID FORMATION1 and the plasma membrane G-protein GPA1 interact in a novel sugar-signaling mechanism in Arabidopsis. Plant Cell 18, 1226-1238. doi: 10.1105/tpc.105.037259

Huang, W., Chen, Q., Zhu, Y., Hu, F., Zhang, L., Ma, Z., et al. (2013). Arabidopsis Thylakoid Formation 1 is a critical regulator for dynamics of PSII-LHCII complexes in leaf senescence and excess light. Mol. Plant 6, 1673-1691. doi: 10.1093/mp/ sst069

Hutagalung, A. H., and Novick, P. J. (2011). Role of Rab GTPases in membrane traffic and cell physiology. Physiol. Rev. 91, 119-149. doi: 10.1152/physrev.000 59.2009

Jedd, G., Mulholland, J., and Segev, N. (1997). Two new Ypt GTPases are required for exit from the yeast trans-Golgi compartment. J. Cell Biol. 137, 563-580. doi: 10.1083/jcb.137.3.563

Kang, B. H., Busse, J. S., and Bednarek, S. Y. (2003). Members of the Arabidopsis dynamin-like gene family, ADL1, are essential for plant cytokinesis and polarized cell growth. Plant Cell 15, 899-913. doi: 10.1105/tpc.009670

Kang, B.-H., Busse, J. S., Dickey, C., Rancour, D. M., and Bednarek, S. Y. (2001). The Arabidopsis cell plate-associated dynamin-like protein, ADL1Ap, is required for multiple stages of plant growth and development. Plant Physiol. 126, 47-68. doi: 10.1104/pp.126.1.47

Karim, S., Alezzawi, M., Garcia-Petit, C., Solymosi, K., Khan, N. Z., Lindquist E., et al. (2014). A novel chloroplast localized Rab GTPase protein CPRabA5e is involved in stress, development, thylakoid biogenesis and vesicle transport in Arabidopsis. Plant Mol. Biol. 84, 675-692. doi: 10.1007/s11103-0130161-x

Keen, J. H. (1990). Clathrin and associated assembly and disassembly proteins. Annu. Rev. Biochem. 59, 415-438. doi: 10.1146/annurev.bi.59.070190. 002215

Keller, R., and Schneider, D. (2013). Homologs of the yeast Tvp38 vesicle-associated protein are conserved in chloroplasts and cyanobacteria. Front. Plant Sci. 4:467 doi: 10.3389/fpls.2013.00467

Keren, N., Ohkawa, H., Welsh, E. A., Liberton, M., and Pakrasi, H. B. (2005) Psb29, a conserved 22-kD protein, functions in the biogenesis of photosystem II complexes in synechocystis and Arabidopsis. Plant Cell 17, 2768-2781. doi: 10.1105/tpc.105.035048

Khan, N. Z., Lindquist, E., and Aronsson, H. (2013). New putative chloroplast vesicle transport components and cargo proteins revealed using a bioinformatics approach: an Arabidopsis model. PLoS ONE 8:e59898. doi: 10.1371/journal.pone.0059898

Kim, S.-J., and Brandizzi, F. (2012). News and views into the SNARE complexity in Arabidopsis. Front. Plant Sci. 3:28. doi: 10.3389/fpls.2012.00028

Kirchhausen, T. (2000). Three ways to make a vesicle. Nat. Rev. Mol. Cell Biol. 1, 187-198. doi: 10.1038/35043117

Kirchhausen, T., and Harrison, S. C. (1981). Protein organization in clathrin trimers. Cell 23, 755-761. doi: 10.1016/0092-8674(81)90439-6

Kobayashi, G., Moriya, S., and Wada, C. (2001). Deficiency of essential GTP-binding protein ObgE in Escherichia coli inhibits chromosome partition. Mol. Microbiol. 41, 1037-1051. doi: 10.1046/j.1365-2958.2001.02574.x

Kroll, D., Meierhoff, K., Bechtold, N., Kinoshita, M., Westphal, S., Vothknecht, U. C., et al. (2001). VIPP1, a nuclear gene of Arabidopsis thaliana essential for thylakoid membrane formation. Proc. Natl. Acad. Sci. U.S.A. 98, 4238-4242. doi: 10.1073/pnas.061500998
Lederkremer, G. Z., Cheng, Y., Petre, B. M., Vogan, E., Springer, S., Schekman, R., et al. (2001). Structure of the Sec23p/24p and Sec13p/31p complexes of COPII. Proc. Natl. Acad. Sci. U.S.A. 98, 10704-10709. doi: 10.1073/pnas.191359398

Lee, M. C. S., Miller, E. A., Goldberg, J., Orci, L., and Schekman, R. (2004). Bi-directional protein transport between the ER and Golgi. Annu. Rev. Cell Dev. Biol. 20, 87-123. doi: 10.1146/annurev.cellbio.20.010403.105307

Leung, K. F., Baron, R., and Seabra, M. C. (2006). Thematic review series: lipid posttranslational modifications. geranylgeranylation of Rab GTPases. J. Lipid Res. 47, 467-475. doi: 10.1194/jlr.R500017-JLR200

Li, F., Yi, L., Zhao, L., Itzen, A., Goody, R. S., and Wu, Y.-W. (2014). The role of the hypervariable C-terminal domain in Rab GTPases membrane targeting. Proc. Natl. Acad. Sci. U.S.A. 111, 2572-2577. doi: 10.1073/pnas.1313655111

Lindquist, E., Alezzawi, M., and Aronsson, H. (2014). Bioinformatic indications that COPI- and clathrin-based transport systems are not present in chloroplasts: an Arabidopsis model. PLoS ONE 2:e104423. doi: 10.1371/journal.pone.0104423

Lo, S. M., and Theg, S. M. (2012). Role of vesicle-inducing protein in Plastids 1 in cpTat transport at the thylakoid. Plant J. 71, 656-668. doi: 10.1111/j.1365313X.2012.05020.x

Luque, I., and Ochoa de Alda, J. A. (2014). CURT1, CAAD-containing aaRSs, thylakoid curvature and gene translation. Trends Plant Sci. 19, 63-66. doi: 10.1016/j.tplants.2013.12.004

Luzio, J. P., Pryor, P. R., and Bright, N. A. (2007). Lysosomes: fusion and function. Nat. Rev. Mol. Cell Biol. 8, 622-632. doi: 10.1038/nrm2217

Marin-Navarro, J., Manuell, A. L., and Wu, J. S. P. M. (2007). Chloroplast translation regulation. Photosynth. Res. 94, 359-374. doi: 10.1007/s11120-007-9183-z

Mayer, A. (1999). Intracellular membrane fusion: SNAREs only? Curr. Opin. Cell Biol. 11, 447-452. doi: 10.1016/S0955-0674(99)80064-7

Mellman, I., and Emr, S. D. (2013). A Nobel prize for membrane traffic: vesicles find their journey's end. J. Cell Biol. 203, 559-561. doi: 10.1083/jcb.201310134

Memon, A. R. (2004). The role of ADP-ribosylation factor and SAR1 in vesicular trafficking in plants. Biochim. Biophy. Acta 1664, 9-30. doi: 10.1016/j.bbamem.2004.04.005

Moreau, P., Juguelin, H., Cassagne, C., and Morré, D. J. (1992). Molecular basis for low temperature compartment formation by transitional endoplasmic reticulum of rat liver. FEBS Lett. 310, 223-228. doi: 10.1016/0014-5793(92) 81337-L

Morré, D. J., Morré, J. T., Morré, S. R., Sundqvist, C., and Sandelius, A. S. (1991a). Chloroplast biogenesis. Cell-free transfer of envelope monogalactosylglycerides to thylakoids. Biochim. Biophys. Acta 1070, 437-445. doi: 10.1016/0005-2736(91)90084-L

Morré, D. J., Selldén, G., Sundqvist, C., and Sandelius, A. S. (1991b). Stromal low temperature compartment derived from the inner membrane of the chloroplast envelope. Plant Physiol. 97, 1558-1564. doi: 10.1104/pp.97.4.1558

Muehlethaler, K., and Frey-Wyssling, A. (1959). Development and structure of proplastids. J. Biophys. Biochem. Cytol. 6, 507-512.

Mullins, C., and Bonifacino, J. S. (2001). The molecular machinery for lysosome biogenesis. Bioessays 23, 333-343. doi: 10.1002/bies.1048

Muranaka, A., Watanabe, S., Sakamoto, A., and Shimada, H. (2012). Arabidopsis cotyledon chloroplast biogenesis factor CYO1 uses glutathione as an electron donor and interacts with PSI (A1 and A2) and PSII (CP43 and CP47) subunits. J. Plant Physiol. 169, 1212-1215. doi: 10.1016/j.jplph.2012.04.001

Nevo, R., Charuvi, D., Shimoni, E., Schwarz, R., Kaplan, A., Ohad, I., et al. (2007). Thylakoid membrane perforations and connectivity enable intracellular traffic in cyanobacteria. EMBO J. 26, 1467-1473. doi: 10.1038/sj.emboj.7601594

Nielsen, E., Cheung, A. Y., and Ueda, T. (2008). The regulatory RAB and ARF GTPases for vesicular trafficking. Plant Physiol. 147, 1516-1526. doi: 10.1104/pp.108.121798

Orcl, L., Palmer, D. J., Amherdt, M., and Rothman, J. E. (1993). Coated vesicle assembly in the Golgi requires only coatomer and ARF proteins from the cytosol. Nature 364, 732-773. doi: 10.1038/364732a0

Otters, S., Braun, P., Hubner, J., Wanner, G., Vothknecht, U. C., and Chigri, F. (2013). The first $\alpha$-helical domain of the vesicle-inducing protein in plastids 1 promotes oligomerization and lipid binding. Planta 237 529-540. doi: 10.1007/s00425-0121772-1

Palade, G. (1975). Intracellular aspects of the process of protein synthesis. Science 189, 347-358. doi: 10.1126/science. 1096303

Palfreyman, M. (2009). SNAREs and the V-ATPase: Poised at the Final Steps of Synaptic Vesicle Exocytosis. Ph.D. thesis, University of Utah, Salt Lake City, UT. 
Palmer, J. D. (2000). A single birth of all plastids? Nature 405, 32-33. doi: $10.1038 / 35011184$

Park, J. M., Cho, J. H., Kang, S. G., Jang, H. J., Pih, K. T., Piao, H. L., et al. (1998). A dynamin-like protein in Arabidopsis thaliana is involved in biogenesis of thylakoid membranes. EMBO J. 17, 859-867. doi: 10.1093/emboj/17.4.859

Park, J. M., Kang, S. G., Pih, K. T., Jang, H. J., Piao, H. L., Yoon H. W., et al. (1997). A dynamin-like protein, ADL1, is present in membranes as a highmolecular-mass complex in Arabidopsis thaliana. Plant Physiol. 115, 763-771. doi: 10.1104/pp.115.2.763

Paul, P., Simm, S., Mirus, O., Scharf, K.-D., Fragkostefanakis, S., and Schleiff, E. (2014). The complexity of vesicle transport factors in plants examined by orthology search. PLoS ONE 9:e97745. doi: 10.1371/journal.pone.0097745

Peters, C., and Mayer, A. (1998). $\mathrm{Ca}^{2+} /$ calmodulin signals the completion of docking and triggers a late step of vacuole fusion. Nature 396, 575-580. doi: 10.1038/25133

Pfeffer, S. (2012). Rab GTPase localization and Rab cascades in Golgi transport. Biochem. Soc. Trans. 40, 1373-1377. doi: 10.1042/BST20120168

Poon, P. P., Cassel, D., Spang, A., Rotman, M., Pick, E., Singer, R. A., et al. (1999). Retrograde transport from the yeast Golgi is mediated by two ARF GAP proteins with overlapping function. EMBO J. 18, 555-564. doi: 10.1093/emboj/18.3.555

Popoff, V., Adolf, F., Brügger, B., and Wieland, F. (2011). COPI budding within the Golgi stack. Cold Spring Harb. Perspect. Biol. 3, a005231. doi: 10.1101/cshperspect.a005231

Räntfors, M., Evertsson, I., Kjellberg, J. M., and Stina Sandelius, A. (2000). Intraplastidial lipid trafficking: regulation of galactolipid release from isolated chloroplast envelope. Physiol. Plant. 110, 262-270. doi: 10.1034/j.1399-3054.2000. 110217.x

Robinson, M. S., and Bonifacino, J. S. (2001). Adaptor-related proteins. Curr. Opin. Cell Biol. 13, 444-453. doi: 10.1016/S0955-0674(00)00235-0

Rothman, J. E. (1994). Mechanisms of intracellular protein transport. Nature 372, 55-63. doi: 10.1038/372055a0

Schekman, R., and Orci, L. (1996). Coat proteins and vesicle budding. Science 271, 1526-1533. doi: 10.1126/science.271.5255.1526

Schmitz, A. J., Glynn, J. M., Olson, B. J., Stokes, K. D., and Osteryoung, K. W. (2009). Arabidopsis FtsZ2-1 and FtsZ2-2 are functionally redundant, but FtsZbased plastid division is not essential for chloroplast partitioning or plant growth and development. Mol. Plant 2, 1211-1222. doi: 10.1093/mp/ssp077

Schneider, D., Fuhrmann, E., Scholz, I., Hess, W. R., and Graumann, P. L. (2007). Fluorescence staining of live cyanobacterial cells suggest non-stringent chromosome segregation and absence of a connection between cytoplasmic and thylakoid membranes. BMC Cell Biol. 8:39. doi: 10.1186/1471-2121-8-39

Schwartz, S. L., Cao, C., Pylypenko, O., Rak, A., and Wandinger-Ness, A. (2007). Rab GTPases at a glance. J. Cell Sci. 120, 3905-3910. doi: 10.1242/jcs.015909

Shimada, H., Mochizuki, M., Ogura, K., Froehlich, J. E., Osteryoung, K. W., Shirano, Y., et al. (2007). Arabidopsis cotyledon-specific chloroplast biogenesis factor CYO1 is a protein disulfide isomerase. Plant Cell 19, 3157-3169. doi: 10.1105/tpc.107.051714

Soubannier, V., McLelland, G.-L., Zunino, R., Braschi, E., Rippstein, P., Fon, E. A., et al. (2012). A vesicular transport pathway shuttles cargo from mitochondria to lysosomes. Curr. Biol. 22, 135-141. doi: 10.1016/j.cub.2011.11.057

Spetea, C., and Aronsson, H. (2012). Mechanisms of transport across membranes in plant chloroplasts. Curr. Chem. Biol. 6, 230-243. doi: $10.2174 / 2212796811206030006$

Stenmark, H. (2009). Rab GTPases as coordinators of vesicle traffic. Nat. Rev. Mol. Cell Biol. 10, 513-525. doi: 10.1038/nrm 2728

Südhof, T. C. (2004). The synaptic vesicle cycle. Annu. Rev. Neurosci. 27, 509-547. doi: 10.1146/annurev.neuro.26.041002.131412

Sztul, E., and Lupashin, V. (2009). Role of vesicle tethering factors in the ER-Golgi membrane traffic. FEBS Lett. 583, 3770-3783. doi: 10.1016/i.febslet.2009.10.083

Takai, Y., Sasaki, T., and Matozaki, T. (2001). Small GTP-binding proteins. Physiol. Rev. 81, 153-208.

Tanz, S. K., Kilian, J., Johnsson, C., Apel, K., Small, I., Harter, K., et al. (2012). The SCO2 protein disulphide isomerase is required for thylakoid biogenesis and interacts with LCHB1 chlorophyll a/b binding proteins which affects chlorophyl biosynthesis in Arabidopsis seedlings. Plant J. 69, 743-754. doi: 10.1111/j.1365313X.2011.04833.x

Thellmann, M., Rybak, K., Thiele, K., Wanner, G., and Assaad, F. F. (2010). Tethering factors required for cytokinesis in Arabidopsis. Plant Physiol. 154, 720-732. doi: $10.1104 /$ pp. 110.154286
Trahey, M., and Hay, J. C. (2010). Transport vesicle uncoating: it's later than you think. F1000 Biol. Rep. 2:47. doi: 10.3410/B2-47

Vernoud, V., Horton, A. C., Yang, Z., and Nielsen, E. (2003). Analysis of the small GTPase gene superfamily of Arabidopsis. Plant Physiol. 131, 1191-1208. doi: $10.1104 / \mathrm{pp} .013052$

von Wettstein, D. (1959). The effect of genetic factors on the submicroscopic structures of the chloroplast. J. Ultrastruct. Res. 3, 234-240.

von Wettstein, D. (2001). Discovery of a protein required for photosynthetic membrane assembly. Proc. Natl. Acad. Sci. U.S.A. 98, 3633-3635. doi: 10.1073/pnas.071056598

Vothknecht, U. C., Otters, S., Hennig, R., and Schneider, D. (2012). Vipp1: a very important protein in plastids?! J. Exp. Bot. 63, 1699-1712. doi: 10.1093/jxb/err357

Vothknecht, U. C., and Soll, J. (2005). Chloroplast membrane transport: interplay of prokaryotic and eukaryotic traits. Gene 354, 99-109. doi: 10.1016/j.gene.2005.04.021

Wang, Q., Sullivan, R. W., Kight, A., Henry, R. L., Huang, J., Jones, A. M., et al. (2004). Deletion of the chloroplast-localized Thylakoid formation 1 gene product in Arabidopsis leads to deficient thylakoid formation and variegated leaves. Plant Physiol. 136, 3594-3604. doi: 10.1104/pp.104.049841

Westphal, S., Heins, L., Soll, J., and Vothknecht, U. C. (2001a). Vippl deletion mutant of Synechocystis: a connection between bacterial phage shock and thylakoid biogenesis? Proc. Natl. Acad. Sci. U.S.A. 98, 4243-4248. doi: 10.1073/pnas.061501198

Westphal, S., Soll, J., and Vothknecht, U. C. (2001b). A vesicle transport system inside chloroplasts. FEBS Lett. 506, 257-261. doi: 10.1016/S0014-5793(01)02931-3

Westphal, S., Soll, J., and Vothknecht, U. C. (2003). Evolution of chloroplast vesicle transport. Plant Cell Physiol. 44, 217-222. doi: 10.1093/pcp/pcg023

Wu, W., Elsheery, N., Wei, Q., Zhang, L., and Huang, J. (2011). Defective etioplasts observed in variegation mutants may reveal the light-independent regulation of white/yellow sectors of Arabidopsis leaves. J. Integr. Plant Biol. 53, 846-857. doi: 10.1111/j.1744-7909.2011.01079.x

Yamaoka, S., Shimono, Y., Shirakawa, M., Fukao, Y., Kawase, T., Hatsugai, N., et al. (2013). Identification and dynamics of Arabidopsis adaptor protein-2 complex and its involvement in floral organ development. Plant Cell 25, 2958-2969. doi: 10.1105/tpc.113.114082

Yamatani, H., Sato, Y., Masuda, Y., Kato, Y., Morita, R., Fukunaga, K., et al. (2013). NYC4, the rice ortholog of Arabidopsis THF1, is involved in the degradation of chlorophyll-protein complexes during leaf senescence. Plant J. 74, 652-662. doi: 10.1111/tpj.12154

Yorimitsu, T., and Sato, K. (2012). Insights into structural and regulatory roles of Sec16 in COPII vesicle formation at ER exit sites. Mol. Biol. Cell 23, 2930-2942. doi: 10.1091/mbc.E12-05-0356

Zhang, L., Kato, Y., Otters, S., Vothknecht, U. C., and Sakamoto, W. (2012). Essential role of VIPP1 in chloroplast envelope maintenance in Arabidopsis. Plant Cell 24, 3695-3707. doi: 10.1105/tpc.112.103606

Zhang, X., and $\mathrm{Hu}, \mathrm{J}$. (2010). The Arabidopsis chloroplast division protein DYNAMIN-RELATED PROTEIN5B also mediates peroxisome division. Plant Cell 22, 431-442. doi: 10.1105/tpc.109.071324

Zou, S., Liu, Y., Zhang, X. Q., Chen, Y., Ye, M., Zhu, X., et al. (2012). Modular TRAPP complexes regulate intracellular protein trafficking through multiple Ypt/Rab GTPases in Saccharomyces cerevisiae. Genetics 191, 451-460. doi: 10.1534/genetics.112.139378

Conflict of Interest Statement: The authors declare that the research was conducted in the absence of any commercial or financial relationships that could be construed as a potential conflict of interest.

Received: 21 June 2014; accepted: 28 August 2014; published online: 23 September 2014.

Citation: Karim S and Aronsson H (2014) The puzzle of chloroplast vesicle transportinvolvement of GTPases. Front. Plant Sci. 5:472. doi: 10.3389/fpls.2014.00472

This article was submitted to Plant Traffic and Transport, a section of the journal Frontiers in Plant Science.

Copyright (C) 2014 Karim and Aronsson. This is an open-access article distributed under the terms of the Creative Commons Attribution License (CC BY). The use, distribution or reproduction in other forums is permitted, provided the original author(s) or licensor are credited and that the original publication in this journal is cited, in accordance with accepted academic practice. No use, distribution or reproduction is permitted which does not comply with these terms. 